\title{
Immobilization of Lipase on Silver Nanoparticles via Adhesive Polydopamine for Biodiesel Production
}

\author{
Kanchana Dumri ${ }^{1}$ and Dau Hung Anh ${ }^{2}$ \\ ${ }^{1}$ Department of Chemistry and Materials Science Research Center, Faculty of Science, Chiang Mai University, \\ Chiang Mai 50200, Thailand \\ ${ }^{2}$ Research and Development Institute/Department of Chemistry, Faculty of Science and Agricultural Technology, \\ Rajamangala University of Technology Lanna, Chiang Mai 50300, Thailand
}

Correspondence should be addressed to Kanchana Dumri; kdumri@gmail.com and Dau Hung Anh; dauhunganh@hotmail.com

Received 24 May 2014; Revised 23 July 2014; Accepted 1 September 2014; Published 10 September 2014

Academic Editor: Roberto Fernandez Lafuente

Copyright (C) 2014 K. Dumri and D. Hung Anh. This is an open access article distributed under the Creative Commons Attribution License, which permits unrestricted use, distribution, and reproduction in any medium, provided the original work is properly cited.

\begin{abstract}
Biodiesel production technology is competitive in terms of low cost and alternative source of energy which should be not only sustainable but also environmentally friendly. Designing of the lipase immobilization for biodiesel production has a remarkable impact and is still challenging. In this work, biodiesel production from soybean oil was enhanced and facilitated by using a novel biocatalyst consisting of commercial lipase (EC 3.1.1.3), silver nanoparticles, and polydopamine. Silver nanoparticles (AgNPs) were synthesized with a size range of $10-20 \mathrm{~nm}$. Polydopamine (PD) was delivered by the self-polymerization of dopamine in $10 \mathrm{mM}$ Tris- $\mathrm{HCl} \mathrm{pH} 8.5$ and simultaneously coated the AgNPs to form a PD/AgNPs complex. Lipase was immobilized on the PD/AgNPs complex surface via covalent bonds to form a tailor-made biocatalyst consisting of immobilized lipase/PD/AgNPs complex (LPA). The formation and morphology of each composition were characterized by UV-Vis spectroscopy and scanning electron microscope (SEM). Significantly, gas chromatography analysis showed a remarkable biodiesel production yield of $95 \%$ by using the LPA complex at $40^{\circ} \mathrm{C}$ for 6 -hours reaction time, whereas the yield was $86 \%$ when using free lyophilized lipase. The LPA complex was apparently reusable after 7 batches and the latter conversion rate of soybean oil was decreased by only $27 \%$.
\end{abstract}

\section{Introduction}

Biodiesel production from vegetable oil has been increasing in the last decade in ASEAN countries, for example, Thailand, Malaysia, Indonesia, Vietnam, and The Philippines, since many of them have diverse and high yield crops of oleaginous plants, for example, palm, soybean, and sunflower $[1,2]$. This is relevant to the world's rapid industrialization and increasing population [3]. For example, since 2010, Thailand had already thirteen active biodiesel producers with a capacity of 1970-million-liter biodiesel B100 or unblended biodiesel. In the year 2012, biodiesel consumption increased by 35\% [4]. Transesterification of vegetable oils by short chain alcohols (methanol or ethanol) catalyzed by lipase (EC 3.1.1.3) is a worldwide biochemical mechanism to produce biodiesel [5] and there are two modes of lipase usage: free or soluble lipase and immobilized lipase. In early 2001, using free lipases from Candida rugosa and Pseudomonas cepacia along with methanol as acyl acceptor, a method was reported to yield biodiesel from soybean oil up to 80 and $90 \%$, respectively [6]. However, free lipase based technology is costly and the reaction rate is low $[7,8]$. Immobilized lipase methods have been introduced to improve lipase stability and reusability. Herein immobilized enzymes are defined as "enzyme physically confined or localized in a certain defined region of space with retention of their catalytic activities, which can be used repeatedly and continuously" [9]. Employed lipases for immobilization have been derived from microorganisms to animals, for example, from pancreatic porcine, Burkholderia cepacia, Pseudomonas spp., and Candida spp. $[8,10]$. Immobilization methods are also various, for example, adsorption on acrylic resin, celite, and anion resin, covalent bonding 
using silica-PVA and styrene-divinylbenzene, entrapment using hydrophobic sol-gel support, and cross-linking using glutaraldehyde [10]. These methods can yield biodiesel from soybean oil using adsorbed lipase [11] and from mahua oil using cross-linked lipase [12]. However, these techniques are still sophisticated and require multiple-steps material consumption in case of Pseudomonas cepacia cross-linked lipase [12], as well as time consumption for oil transesterification (49 hour) in case of absorbed Pseudomonas fluorescens lipase on macroporous polypropylene matrix [11].

In recent years, dopamine, an adhesive protein from mussel, has been found and applied for multifunctional coatings in surface $[13,14]$. Dopamine contains catechol and amine functional groups. It can self-polymerize in alkaline environments to form thin adherent polydopamine (PD) on a wide range of materials including noble metals (e.g., Ag and $\mathrm{Au}$ ) and iron oxide [13-15]. Polydopamine has also been studied for enzyme immobilization, for example, trypsin [16], glucose oxidase [17], and lipase [18]. Enzymes can be covalently immobilized on a polydopamine surface via nucleophiles [19]. On the other hand, silver nanoparticles (AgNPs) have been known to exhibit nonspecific antibacterial property in silver-based biomolecule coatings [20-23]. Since biodiesel production technology is competitive in terms of low cost and reusability of materials, ASEAN countries are increasingly producing biofuels. To this end, we carried out the synthesis of a novel biocatalyst consisting of porcine pancreatic lipase/polydopamine/silver nanoparticles. Here we describe its apparent biochemical and morphological properties and its application in biodiesel production from the soybean oil which is the one of the dominant productivity of oil plant in the Northern Thailand [24, 25].

\section{Materials and Methods}

2.1. Materials. Porcine pancreatic lipase (EC 3.1.1.3), dopamine hydrochloride, standard fatty acids, and fatty acid methyl ester were purchased from Sigma-Aldrich (Germany). Other chemicals were of analytical grade. Soybean oil was obtained from commercial supplier (Chiang Mai, Thailand).

2.2. Synthesis of Biocomplex Consisting of Immobilized Lipase, Polydopamine, and Silver Nanoparticles (LPA Complex). AgNPs of size 2-20 nm were synthesized as described by Solomon et al. (2007) [26]. $20 \mathrm{~mL}$ of colloidal AgNPs solution was mixed well with $20 \mathrm{~mL}$ of Tris- $\mathrm{HCl}$ buffer $20 \mathrm{mM}(\mathrm{pH}$ 8.5). Afterwards, $100 \mathrm{mg}$ dopamine hydrochloride was added stepwise (approximately $2 \mathrm{mg} / 15 \mathrm{~s}$ ) to a vigorously stirred AgNPs solution at room temperature for 1 hour to form polydopamine/AgNPs complex (PD/AgNPs). Afterwards, $40 \mathrm{~mL}$ of $\mathrm{PD} / \mathrm{AgNPs}$ mixture solution was added dropwise $(100 \mu \mathrm{L} / 15 \mathrm{~s})$ to a vigorously stirring $40 \mathrm{~mL}$ lipase solution (100 mg lyophilized lipase and sodium phosphate buffer $10 \mathrm{mM}, \mathrm{pH} 7.0$ ) for 3 hours, $180 \mathrm{rpm}$ at $4^{\circ} \mathrm{C}$. The formation of an amorphous immobilized lipase/PD/AgNPs complex was observed immediately after addition of lipase solution. The LPA complex was collected for centrifugation and stored at $4^{\circ} \mathrm{C}$ prior to further experiment. A polydopamine/AgNPs complex without enzyme was used as negative control. For the immobilization yield, supernatant was taken for lipase activity measurement as described below and protein concentration was determined as described by Bradford [27].

\subsection{Enzyme Assays for Soluble Lipase and Immobilized Lipase.} Lipase activity was determined spectrophotometrically at $232 \mathrm{~nm}$ following the hydrolysis of $1 \%(\mathrm{w} / \mathrm{v})$ Tween 80 as substrate in Tris-HCl buffer $(20 \mathrm{mM}, \mathrm{pH} 8.5)$ containing $80 \mathrm{mM} \mathrm{CaCl}_{2}$ (designated as substrate solution). Reaction was carried out at $25^{\circ} \mathrm{C}$ (modified from [28]). The activity of authentic soluble lipase $(1.25 \mathrm{mg} / \mathrm{mL}$ in $10 \mathrm{mM}$ sodium phosphate butter $\mathrm{pH} 7.0$ ) was measured by adding of $100 \mu \mathrm{L}$ of enzyme solution to $900 \mu \mathrm{L}$ reaction mixture consisting of $800 \mu \mathrm{L}$ sodium phosphate buffer and $100 \mu \mathrm{L}$ substrate solution. The hydrolysis rate of Tween 80 was directly monitored by measuring the decrease of absorbance at $232 \mathrm{~nm}$ over $10 \min [28]$.

For the determination of immobilized enzyme activity, $1 \mathrm{~mL}$ LPA complex in a $2 \mathrm{~mL}$ Eppendorf tube was centrifuged at $5000 \mathrm{rpm}$ for $5 \mathrm{~min}$. Supernatant was replaced by $1 \mathrm{~mL}$ of deionized water and the pellet was vortexed for $1 \mathrm{~min}$ at $180 \mathrm{rpm}$ for washing. This washing step was repeated 3 times and then the pellet was mixed with $1 \mathrm{~mL}$ reaction mixture containing $100 \mu \mathrm{L}$ substrate solution and $900 \mu \mathrm{L}$ sodium phosphate buffer $(10 \mathrm{mM}, \mathrm{pH} 7.0)$. The reaction mixture was vigorously vortexed at $180 \mathrm{rpm}$ for $10 \mathrm{~min}$ at room temperature. Afterwards, it was centrifuged at $5000 \mathrm{rpm}$ for $5 \mathrm{~min}$ and $100 \mu \mathrm{L}$ of supernatant was dissolved in $900 \mu \mathrm{L}$ sodium phosphate buffer. The absorbance of the latter was measured at $232 \mathrm{~nm}$ and related to the activity of immobilized lipase in the LPA complex by comparison with authentic soluble lipase activity.

For assessment of enzyme immobilization yield, $1 \mathrm{~mL}$ LPA complex in a $2 \mathrm{~mL}$ Eppendorf tube was centrifuged at $5000 \mathrm{rpm}$ for $5 \mathrm{~min}$. Afterwards, $100 \mu \mathrm{L}$ of supernatant was taken for soluble lipase activity measurement as described above.

2.4. UV-Vis Spectroscopy Study. UV-Vis spectra of colloidal silver nanoparticles, $\mathrm{PD} / \mathrm{AgNPs}$, and immobilized lipase/PD/AgNPs complex were recorded in the range of 200-800 nm using a Lambda Bio 20 UV Spectrophotometer (Perkin Elmer, USA). For these experiments, $50 \mu \mathrm{L}$ of sample was mixed well with $950 \mu \mathrm{L}$ sodium phosphate buffer $(10 \mathrm{mM}$, $\mathrm{pH} 7.0)$.

2.5. Characterization of AgNPs, PD/AgNPs, and LPA Complexes by Scanning and Transmission Electron Microscopy (SEM and TEM). The morphologies and dimensions of samples were characterized by SEM and TEM (JEM 5910 LV and JEM 1010 JOEL Ltd., Japan) with accelerating voltage of $15 \mathrm{kV}$ and $80 \mathrm{kV}$, respectively, with fit magnification.

2.6. Study on Optimal Temperature and Thermal Stability of Soluble and Immobilized Lipase. The temperature dependence of immobilized lipase activity was investigated in temperature range from 30 to $55^{\circ} \mathrm{C}$ in comparison to soluble 
lipase and activities of both forms were determined as described in Section 2.3. The thermal stability of immobilized lipases was investigated by determining its activity at optimal operating temperature after incubation period at $0,2,4$, and 6 hours [29].

2.7. Biodiesel Production. Reaction was performed in a $100 \mathrm{~mL}$ Duran bottle containing $5 \mathrm{~g}$ soybean oil and $15 \mathrm{~g}$ $\mathrm{MeOH}$. For the conversion of soybean oil, $\mathrm{MeOH}$ was added at the reaction times 0,2 , and 4 hours ( 5 g each time, i.e., $15 \mathrm{~g}$ in total). This stepwise addition of $\mathrm{MeOH}(3 \times 5 \mathrm{~g})$ to reach an oil to $\mathrm{MeOH}$ ratio of $1: 3(\mathrm{w} / \mathrm{w})$ was implemented because this strategy has been widely proposed for biodiesel production studies [10]. An appropriate amount of immobilized lipase/PD/AgNPs (i.e., pellet LPA complex that was collected after centrifugation) or lyophilized lipase was applied. The reaction mixture was continuously stirred at $120 \mathrm{rpm}$ for 6 hours at $40^{\circ} \mathrm{C}$ (optimal conditions). For reusability tests, the reaction mixture was centrifuged at $5000 \mathrm{rpm}$ for $30 \mathrm{~min}$ at $4^{\circ} \mathrm{C}$ to collect the immobilized lipase pellet and the pellet was then reused with fresh substrates for further batch of biodiesel production.

2.8. Gas Chromatography Analysis of Soybean Oil. Soybean oil was identified using a HP6890 gas chromatograph equipped with a capillary column (AT-5, $30 \mathrm{~m} \times 0.25 \mathrm{~mm}$ I.D. $\times 0.25 \mu \mathrm{m}$ film thickness) and fitted with FID detector. The column temperature was increased from $150^{\circ} \mathrm{C}$ to $300^{\circ} \mathrm{C}$ at a rate of $4^{\circ} \mathrm{C} / \mathrm{min}$ and maintained for $3 \mathrm{~min}$ at $300^{\circ} \mathrm{C}$. Fatty acids were calculated by comparing the retention times and peaks between sample and authentic standards (palmitic acid, stearic acid, oleic acid, linoleic acid, and linolenic acid; SigmaAldrich).

2.9. Fatty Acid Methyl Esters (FAMEs) Analysis (Biodiesel Products). $0.5 \mathrm{~mL}$ of reaction mixture was mixed with $1.0 \mathrm{~mL}$ isooctane for $2 \mathrm{~min}$. Following centrifugal separation, the organic upper layer was collected and washed twice with distilled water and dried over anhydrous $\mathrm{Na}_{2} \mathrm{SO}_{4}$. The solvent was dried under $\mathrm{N}_{2}$ steam and dissolved in $0.25 \mathrm{~mL}$ of $\mathrm{CH}_{2} \mathrm{Cl}_{2}$. The previous $\mathrm{GC}$ condition of soybean oil analysis was applied. FAMEs formations were analyzed by means of authentic fatty acid methyl ester standards (methyl palmitate, methyl stearate, methyl oleate, methyl linoleate, and methyl linolenate; Sigma-Aldrich).

\section{Results and Discussion}

3.1. Characterization of AgNPs, PD/AgNPs, and LPA Complexes. The AgNPs, which were synthesized by $\mathrm{NaBH}_{4}$, were selected by the following reasons: (1) they can be used as a supporting core for the lipase immobilization to enhance the stability of lipase and to build morphologically controllable particles; (2) their size could be controlled, from 10 to $20 \mathrm{~nm}$ in diameters, so the smaller size particles will enlarge the total acting surface of reacting silver particles in reaction mixture. Obviously, this would lead to higher binding amount and volume of polydopamine and therefore the
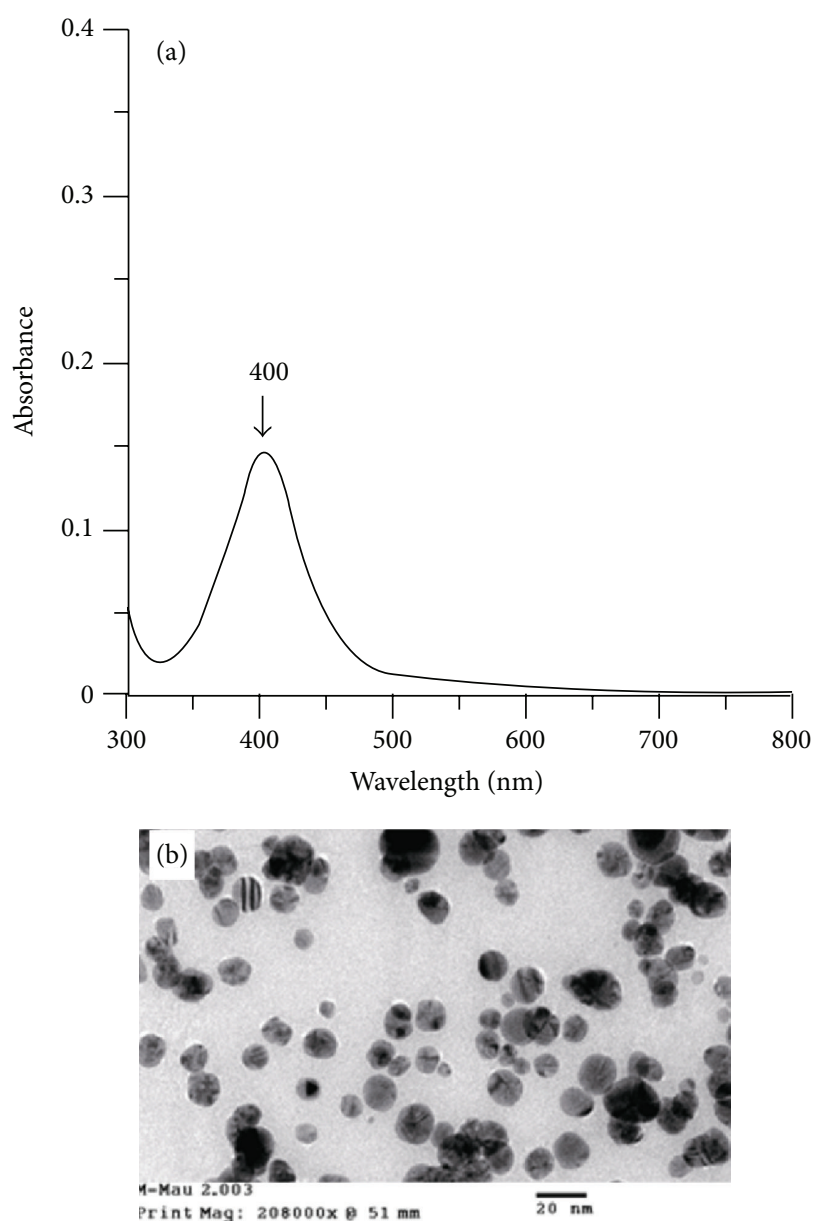

FIgURE 1: Typical UV-Vis spectrum (a) and TEM image (b) of silver nanoparticles.

silver nanoparticle/polydopamine complex can trap lipase molecules massively; (3) colloidal AgNPs are not precipitated and agglomerated; hence they facilitate the uniform coating of polydopamine, and (4) they contribute to the probable antibacterial property of the biocatalyst as described in works where AgNPs were used to produce materials with antibacterial properties, for example, nanocomposites [30, 31]. Herein, AgNPs synthesis was modified from previous report [26] by increasing the $\left[\mathrm{NaBH}_{4}\right]$ to $\left[\mathrm{AgNO}_{3}\right]$ ratio to $10: 1$ to oxidize the $\mathrm{AgNO}_{3}$ completely to $\mathrm{Ag}$. The colloidal AgNPs were yellowish and had a characteristic absorption spectrum with one maximum at $400 \mathrm{~nm}$ (Figure 1(a)). The TEM image in Figure 1(b) reveals the high density of the colloidal AgNPs sample. Particle sizes are approximately 10$20 \mathrm{~nm}$.

For the next step to form the PD/AgNPs complex, the selfpolymerization of dopamine in alkaline $\mathrm{pHs}$ [14] can form a thin polydopamine layer on noble metals [15]. Polydopamine has a robust polymerized aromatic structure and its formation is influenced by operating temperature, $\mathrm{pH}$, and concentration of the dopamine solution [32]. In our experimental design, dopamine was selectively used to coat AgNPs to generate the PD/AgNPs complex, which were greenish black. 
In addition, previous works on coating dopamine have also suggested that an antibacterial surface was created by AgNPs composite $[20,23,33]$. Therefore, we assume that the presence of surfaced AgNPs herein alternatively protects the active lipase from bacterial degradation in different performance $[34,35]$ and probably allows the immobilized lipases to remain their activities for further approach.

The absorption spectrum behavior of $\mathrm{PD} / \mathrm{AgNPs}$ (Figure 2(a)) has one distinguishable maximum at $275 \mathrm{~nm}$ and no representative peak for AgNPs at $400 \mathrm{~nm}$. It can be deduced that AgNPs were covered and entrapped by PD and thus could not be detected by UV-Vis spectroscopy. SEM image in Figure 2(b) shows the PD/AgNPs agglomerates with size of approximately $200 \mathrm{~nm}$. Diverse surfaces sizes of polydopamine were reported with sizes from $4 \mathrm{~nm}$ to over $100 \mathrm{~nm}$ by means of thin film $[20,32,36]$.

Figure 2(c) reveals the bright spots clustered on a dark grey matrix, which are represented for AgNPs. These demonstrate that AgNPs could be partly captured on the surface of the PD/AgNPs complex. By means of capturing AgNPs on the $\mathrm{PD} / \mathrm{AgNPs}$ complex surface, the PD/AgNPs complex could possibly exhibit antibacterial growth property [20,31].

The most important step was for immobilized lipase to form the complete complex with PD/AgNPs. Lipase from porcine pancreas was immobilized on the PD/AgNPs complex via covalent bonds between the active quinone groups of PD and the amine and thiol groups of lipase $[14,19]$. The polymerization of dopamine generates active residual quinones which allow covalent immobilization of the protein via Michael addition of cysteine (Cys), histidine (His), and lysine (Lys) residues of the lipase from porcine pancreas as well as Shiff base formation $[14,19,36]$. Thus, there is no need to use coupling reagents (e.g., glutaraldehyde or (3-aminopropyl) triethoxysilane) which require sophisticated procedures and may influence the protein structure $[10,37,38]$.

In this work, a black precipitate was formed immediately after addition of lipase to the PD/AgNPs solution. The absorbance spectrum of the lipase-immobilized PD/AgNPs complex solution has a unique maximum at $280 \mathrm{~nm}$ (Figure 3(a)). The lipase immobilization on the PD/AgNPs complex with a ratio of lipase/PD of $1: 1(\mathrm{w} / \mathrm{w})$ changed the typical spectrum of the PD/AgNPs complex. The high background in the spectrum possibly resulted from the black particles in the sample solution. The loaded lipase is assumed to be immobilized entirely onto the surface of the PD/AgNPs complex. The SEM image in Figure 3(b) demonstrates the homologous morphology of the lipase/PD/AgNPs agglomerates with an average size of $50-100 \mathrm{~nm}$ and they are not similar to the PD/AgNPs complex. The formation of separate particle chains can imply that the immobilization of lipase sharpens the PD/AgNPs complex from 200 to smaller $100 \mathrm{~nm}$ blocks by uncertain mechanisms. The spherical morphology of the LPA complex may be caused by the SEM sample preparation. On the other hand, this obtained LPA shape might contribute to the hydrolysis yield of vegetable oil by means of its random porous and interfacial structures. It might help to shear oil droplets to smaller sizes during transesterification that takes place under vigorous stirring
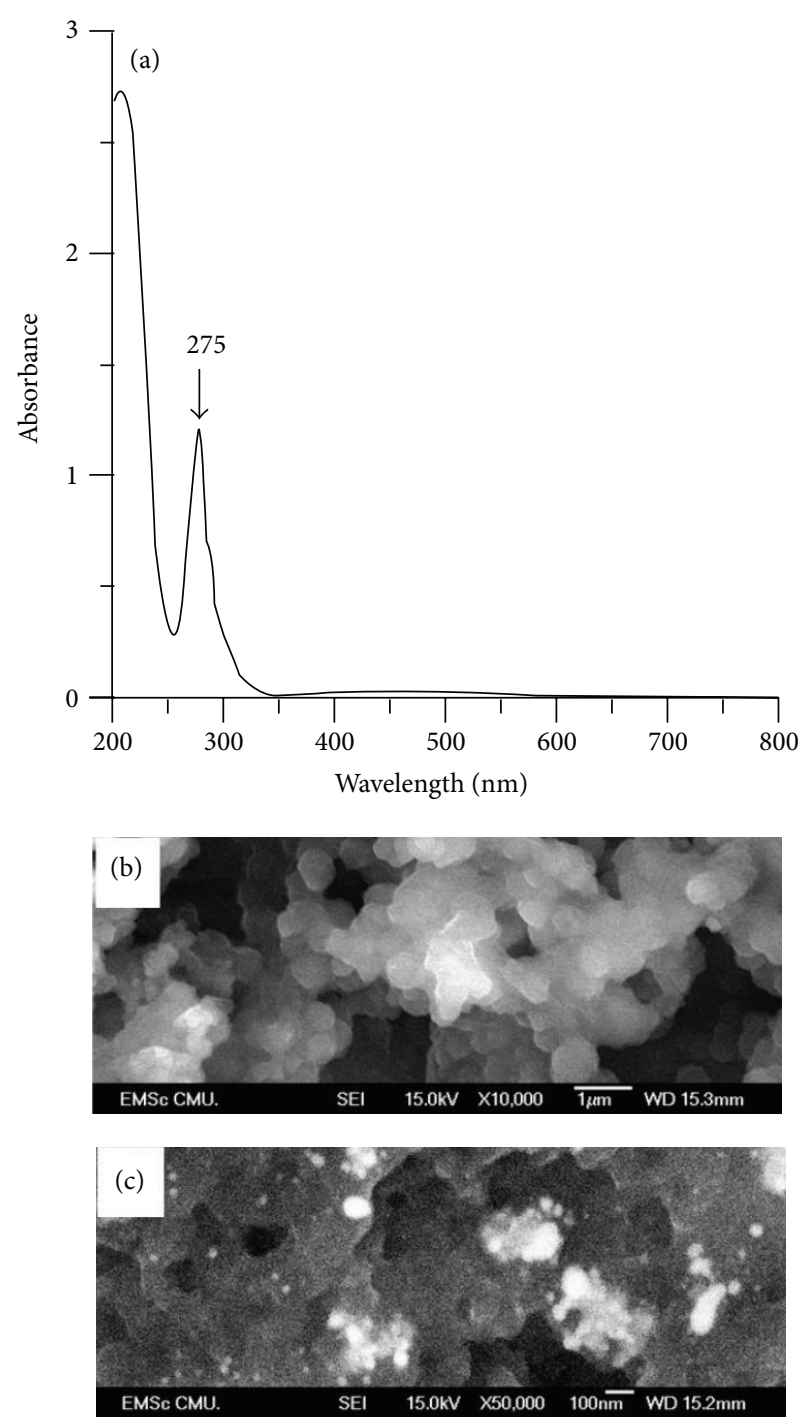

FIGURE 2: Typical UV-Vis spectrum (a) and SEM images ((b), (c)) of polydopamine (PD) and silver nanoparticles (AgNPs) complex.

and heating condition. It might also increase the access and exposure of lipid substrate to active site of immobilized lipases and lipid substrate molecules would be retained in porous matrix to react with the interfacial lipase in an appropriate time.

\subsection{Fast Lipase Immobilization and Hydrolyzing Activity of} Immobilized Lipase. The apparent protocol for immobilization allows the complete immobilization when the loading lipase/dopamine weight ratio was $1: 1$ and concentrations of both loading lipase and dopamine were $1.25 \times 10^{-3}(\mathrm{w} / \mathrm{v})$ in a total reaction volume of $80 \mathrm{~mL}$. In the aqueous phase that was collected after centrifugation of the LPA complex solution, we could observe no lipase activity toward hydrolyzing of Tween 80 or it might be too low to detect enzyme activity. On the other hand, Bradford test of the residue of loading lipase protein after immobilization showed that $92 \mathrm{mg}$ loading lipase took part in immobilization when $100 \mathrm{mg}$ dopamine was 

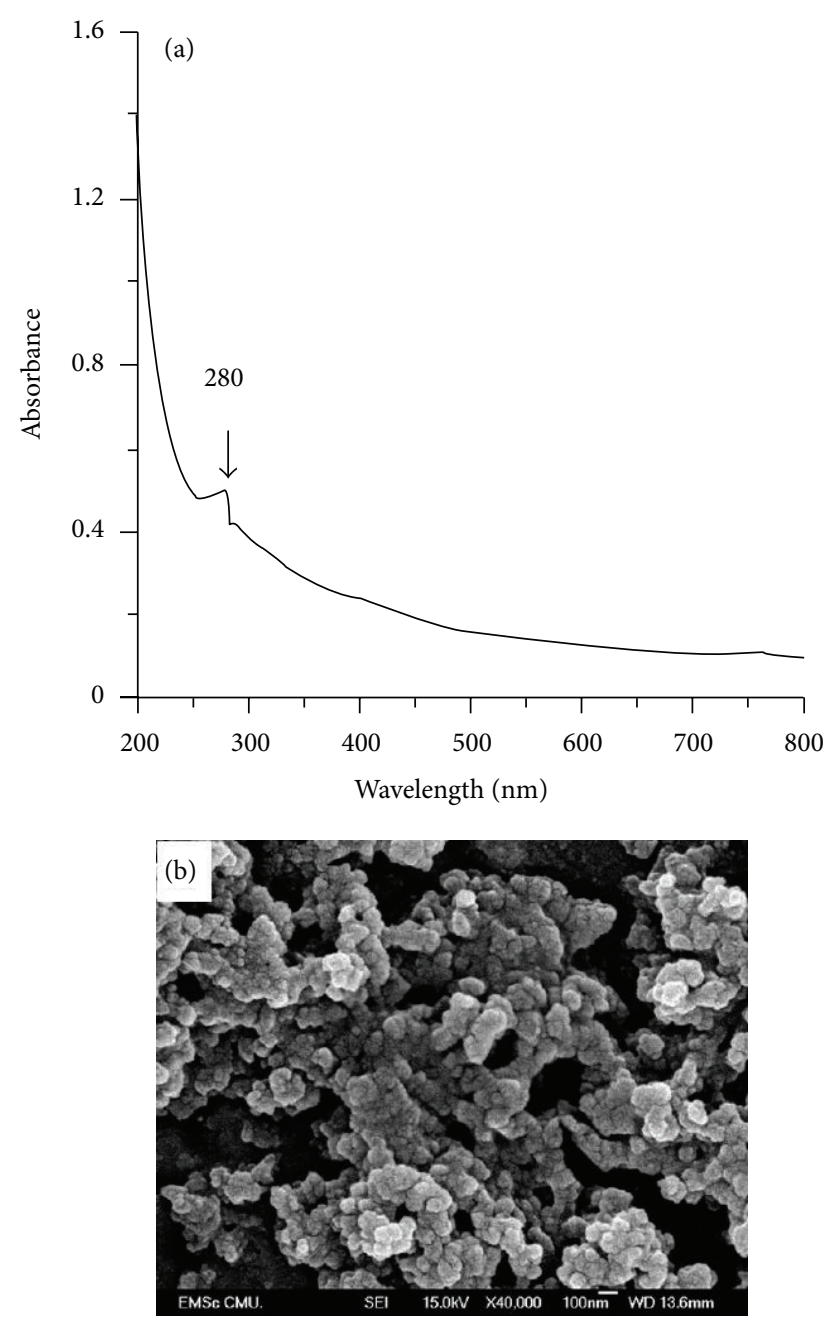

FIgure 3: Typical UV-Vis spectrum (a) and SEM images (b) of immobilized lipase adhesive with PD/AgNPs complex.

used to cover a given AgNPs. Taken into consideration, this technique gives higher immobilization yield in comparison to $60-85 \%$ in case of covalent bond based immobilization using polyglutaraldehyde activated styrene-divinylbenzene (STYDVB-PGA) for lipase from Thermomyces lanuginosus [39, 40] and silica-polyvinyl alcohol for lipase from Burkholderia cepacia [41]. As other heterogeneous biocatalysts, not only the mass transfer limitation but also the ratio of enzyme/support matrix $(w / w)$ is taken into consideration. In our experiment the ratio of lipase/dopamine (i.e., lipase/support matrix; w/w) was to $1: 1$, whereas it was approximately $1: 5$ when using $\beta$-cyclodextrin/hexamethylene diisocyanate [42] and 1:100 when using STY-DVB-PGA [41]. This may have physically increased the exposure of immobilized lipase to substrates and enhanced the catalytic property of the LPA complex. In addition, the instant self-polymerization of dopamine curtails the time consumption. The entire immobilization process herein required 4 hours. In comparison, previous reports required up to $24-30$ hours [37, 41, 43]. Hence, this can reduce the degeneration of the lipase while immobilizing occurs. The correlative lipase activity of the LPA complex (i.e., immobilized lipase) was assumed as approximately 25.2 U/mg LPA complex in comparison with $23.9 \mathrm{U} / \mathrm{mg}$ lyophilized lipase (dimension U/mg materials). In other words, a given polydopamine-immobilizing lipase quantity might have approximately 2.2-fold higher activity in comparison to similar quantity of lyophilized lipase towards Tween 80 as substrate in this work. Related to the described morphology of LPA complex (Figure 3(b)), previous work reported the interfacial Candida rugosa lipase giving a higher activity than in the bulk [44]. Thus, a possibly similar mechanism might have occurred in our case study.

The use of polydopamine gives not only the higher immobilization efficiency but also the activity of bound enzyme, and it was in concurrence with a report elsewhere [18]. We achieved an immobilized lipase on the PD/AgNPs complex and this biocatalyst complex remarkably demonstrated higher hydrolyzing activity than previous reports [42, 45]. This can be related to different immobilization techniques, for example, adsorption, entrapment, and polymer-based supports, for example, natural polymers such as alginate, chitosan, or polydopamine, synthetic polymers such as polyvinyl chloride and polyaniline [10], and inorganic materials such as silica, glass, or activated carbon [18, 42, 45].

3.3. Optimal Temperature and Thermal Stability. Utilization of lipase enzymes in industrial processes, especially biodiesel production, often meets the challenge of thermal inactivation. Figure 4 illustrates the similar optimal temperature for soluble lipase and lipase/PD/AgNPs complex at $40^{\circ} \mathrm{C}$. We assume that the polydopamine matrix does not influence practically the activating energy of lipase hydrolysis. Significantly, at high temperatures of 45,50 , and $55^{\circ} \mathrm{C}$, immobilized lipase activities were higher than those of soluble lipase from approximately 10 to $20 \%$. It was identical to 2,4,6-trichloros-triazine activated polyvinyl alcohol-immobilizing porcine pancreatic lipase [46]. By means of this, our work contributes to knowledge of lipase immobilization with regards to temperature resistance since over $80 \%$ relevant works use immobilized lipases [8]. Hence, the optimal temperature $40^{\circ} \mathrm{C}$ was applied throughout biodiesel production experiments.

Thermal stability of the soluble and immobilized lipase at $40^{\circ} \mathrm{C}$ was consequently determined as illustrated in Figure 5. After 6-hour incubation, the immobilized lipase still maintained the high activity at 95\%, whereas the native lipase activity decreased after 2 hours to $60 \%$ and dramatically dropped to $40 \%$ after 6 -hour incubation. This phenomenon was similar to previous reports $[18,37,47]$ in which the immobilized lipase is obviously stable in comparison to soluble native form in terms of long incubation period at high temperature. Taken into consideration, the thermal stability of LPA complex will be useful when it would have been applied to increase hydrolysis yield by extending of incubation time and to treat recalcitrant substrates, for example, waste cooking oil, in near future.

3.4. Conversion of Soybean Oil by LPA Complex. For the biodiesel production experiment, an approximately $10 \mathrm{mg}$ of 


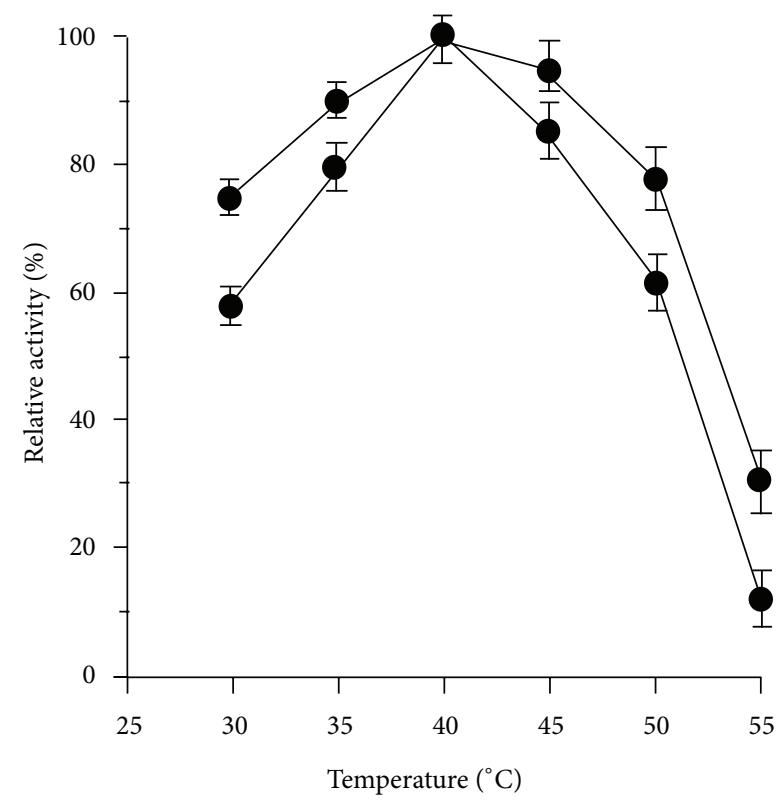

FIgURE 4: Influence of temperature on the activity of immobilized lipase ( $\mathbf{\square}$ ) and soluble lipase (๑). Data points are means for three parallel measurements $(\mathrm{SD}<10 \%)$.

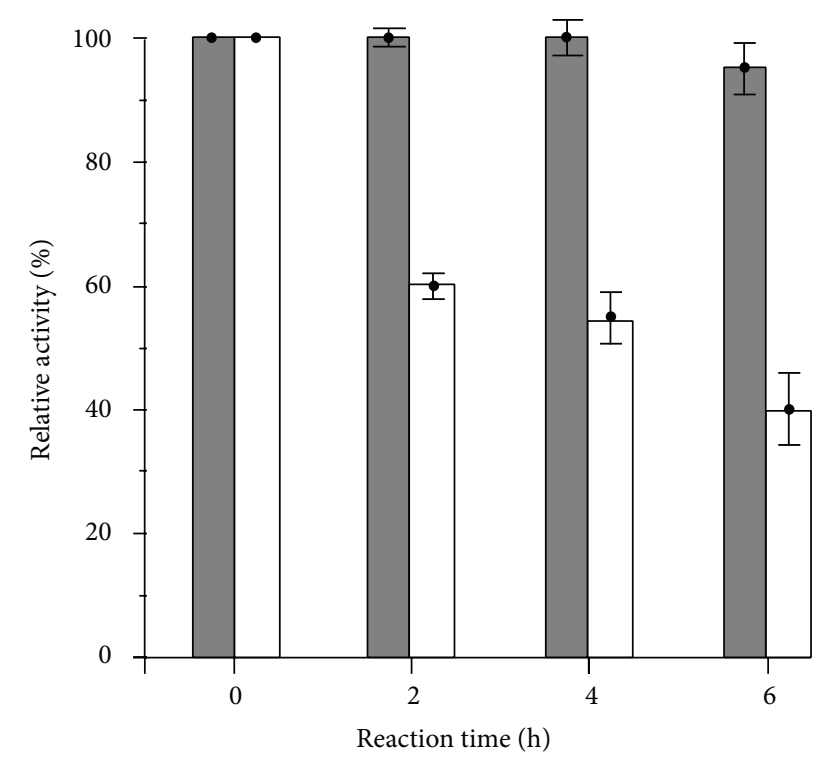

FIGURE 5: Thermal stability of immobilized lipase (dark bars) and soluble lipase (white bars) activity at $40^{\circ} \mathrm{C}$. Data points are means for three parallel measurements $(\mathrm{SD}<10 \%)$.

the LPA complex and $20 \mathrm{mg}$ of lyophilized lipase (approximately $478 \mathrm{U}$ towards the hydrolysis of Tween 80 ) were taken for transesterification of soybean oil with $\mathrm{MeOH}$ at $40^{\circ} \mathrm{C}$ for 6 hours (optimal conditions). The fatty acid compositions of soybean oil sample were detected including linoleic acid (50\%), oleic acid (25\%), palmitic acid (10\%), linolenic acid $(8 \%)$, and stearic acid (4\%). The results showed that soybean oil conversion rate by immobilized lipase was higher than free lipase (Figure 6). GC analysis of FAMEs showed that the
LPA complex could produce biodiesel product at up to $95 \%$ whereas the free lipase (lyophilized lipase was directly added to reaction mixture) could give $86 \%$ at $40^{\circ} \mathrm{C}$ after 6 -hour reaction time. Comparatively, LPA complex was effective for biodiesel production from soybean oil when soybean oil conversion yield was 65 and $80 \%$ by using lipase from Pseudomonas cepacia and Rhizomucor miehei, respectively [48]. In other cases, the mixture of immobilized Rhizopus oryzae and Candida rugosa lipases was reported to give soybean conversion at $99 \%$ but the transesterification consumed 21 hours $[49,50]$. Herein, simple covalent bondingbased immobilization technique by using polydopamine as supporting matrix is very promising to increase the biodiesel production yield since the lipase structure is probably not altered during interaction with other immobilizing compositions.

3.5. Reusability of Immobilized Lipase for Transesterification. In terms of potential industrial application, the immobilization of lipase influences economic aspects not only by saving chemical reagents and reducing reaction time, but also through reusability. Remarkably, the conversion yield of soybean oil using the reused LPA complex was only decreased by approximately $27 \%$ after seven consecutive batches. The time lapse between batches was 2 days (Figure 7). The gradual decrease of oil conversion yield clearly occurred by the loss of activity of immobilized lipase. This probably happens due to the aggregation of LPA during separation by centrifugation, washing by $\mathrm{MeOH}$, and lipase denaturation by heat and organic reactant $(\mathrm{MeOH})$. Concerning reusability, the LPA complex was separated conveniently from the reaction batch by centrifugation and kept in sodium phosphate buffer $10 \mathrm{mM}, \mathrm{pH} 8.5$ at $4^{\circ} \mathrm{C}$ without any protein preservative. Therefore, the fact of immobilization of lipase via adhesive of AgNPs and polydopamine could improve its thermal stability and show a high catalytic activity under the employed conditions. This approach could allow its utilization in transesterification of soybean oil to produce biodiesel products.

\section{Conclusions}

Biodiesel has been gaining prominence in recent years as a viable, alternative fuel to mineral-based fossil fuel diesel. The application of lipase as biocatalyst in transesterification of plant oils for biodiesel production offers an environmentally impact more attractive option compared to the conventional process. In this work, we described an alternative novel method to immobilize lipase on silver nanoparticles through an adhesive polydopamine. Our results showed that LPA complex exhibited the biodiesel products up to $95 \%$ yield. Importantly, the LPA complex displayed good reusability as well as the convenience to be centrifugally recovered.

\section{Conflict of Interests}

The authors declare that there is no conflict of interests regarding the publication of this paper. 


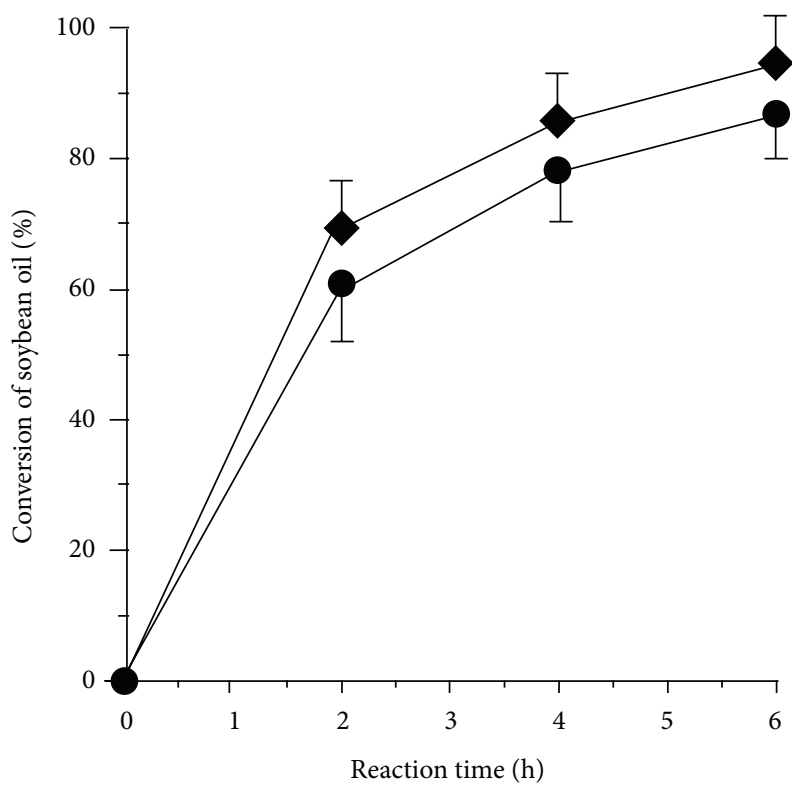

FIGURE 6: Conversion rate of soybean oil to biodiesel products at different reaction time for 6 hours by lipase/PD/AgNPs complex $(\diamond)$ and soluble lipase $(\bullet)$. Data points are means for three parallel measurements $(\mathrm{SD}<10 \%)$.

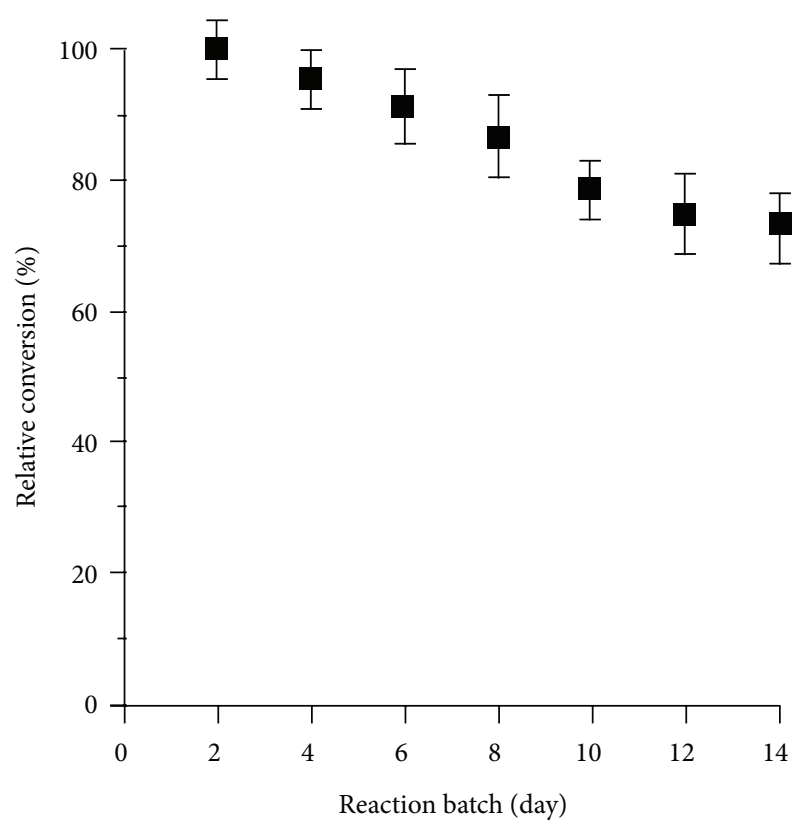

FIGURE 7: Reusability of immobilized lipase for conversion of soybean oil. Data represent maximum conversion rate of the reaction as the function of repeated batch. Data points are means for three parallel measurements $(\mathrm{SD}<10 \%)$.

\section{Acknowledgments}

Financial support by the Dr. Bruno Werdelmann Foundation, Chiang Mai University, Chiang Mai (Thailand), and National Research University Project under Thailand's Office of the Higher Education Commission is gratefully acknowledged.
Authors thank Pornchai Chanta for GC technical assistance and Budsabong Kuntalue for SEM and TEM services.

\section{References}

[1] N. Mukta and Y. Sreevalli, "Propagation techniques, evaluation and improvement of the biodiesel plant, Pongamia pinnata (L.) Pierre-a review," Industrial Crops and Products, vol. 31, no. 1, pp. 1-12, 2010.

[2] H. T. Murphy, D. A. O'Connell, G. Seaton et al., "A common view of the opportunities, challenges, and research actions for pongamia in Australia," Bioenergy Research, vol. 5, no. 3, pp. 778-800, 2012

[3] U. Hoffmann, "Some reflections on climate change, green growth illusions and development space," United Nations Conference on Trade and Development Discussion Papers 205, 2011, http://unctad.org/en/PublicationsLibrary/osgdp2011d5_en.pdf.

[4] S. Preechajarn and P. Prasertsri, "Biofuels Annual Bangkok Thailand 2012," GAIN Report, vol. TH2064, 2012.

[5] X. Fan, X. Niehus, and G. Sandoval, "Lipases as biocatalyst for biodiesel production," Methods in Molecular Biology, vol. 861, pp. 471-483, 2012.

[6] M. Kaieda, T. Samukawa, A. Kondo, and H. Fukuda, "Effect of methanol and water contents on production of biodiesel fuel from plant oil catalyzed by various lipases in a solvent-free system," Journal of Bioscience and Bioengineering, vol. 91, no. 1, pp. 12-15, 2001.

[7] Y. Zhang, M. A. Dubé, D. D. McLean, and M. Kates, "Biodiesel production from waste cooking oil: 1. Process design and technological assessment," Bioresource Technology, vol. 89, no. 1, pp. 1-16, 2003.

[8] L. Fjerbaek, K. V. Christensen, and B. Norddahl, "A review of the current state of biodiesel production using enzymatic transesterification," Biotechnology and Bioengineering, vol. 102, no. 5, pp. 1298-1315, 2009.

[9] K. R. Jegannathan, S. Abang, D. Poncelet, E. S. Chan, and P. Ravindra, "Production of biodiesel using immobilized lipasea critical review," Critical Reviews in Biotechnology, vol. 28, no. 4, pp. 253-264, 2008.

[10] T. Tan, J. Lu, K. Nie, L. Deng, and F. Wang, "Biodiesel production with immobilized lipase: a review," Biotechnology Advances, vol. 28, no. 5, pp. 628-634, 2010.

[11] A. Salis, M. Pinna, M. Monduzzi, and V. Solinas, "Comparison among immobilised lipases on macroporous polypropylene toward biodiesel synthesis," Journal of Molecular Catalysis B: Enzymatic, vol. 54, no. 1-2, pp. 19-26, 2008.

[12] V. Kumari, S. Shah, and M. N. Gupta, "Preparation of biodiesel by lipase-catalyzed transesterification of high free fatty acid containing oil from Madhuca indica," Energy \& Fuels, vol. 21, no. 1, pp. 368-372, 2007.

[13] V. V. Papov, T. V. Diamond, K. Biemann, and J. H. Waite, "Hydroxyarginine-containing polyphenolic proteins in the adhesive plaques of the marine mussel Mytilus edulis," Journal of Biological Chemistry, vol. 270, no. 34, pp. 20183-20192, 1995.

[14] H. Lee, S. M. Dellatore, W. M. Miller, and P. B. Messersmith, "Mussel-inspired surface chemistry for multifunctional coatings," Science, vol. 318, no. 5849, pp. 426-430, 2007.

[15] Y. Bu and S. Lee, "Influence of dopamine concentration and surface coverage of $\mathrm{Au}$ shell on the optical properties of $\mathrm{Au}$, $\mathrm{Ag}$, and $\mathrm{Ag}$ core $\mathrm{Au}_{\text {shell }}$ nanoparticles," ACS Applied Materials and Interfaces, vol. 4, no. 8, pp. 3923-3931, 2012. 
[16] J. G. Rivera and P. B. Messersmith, "Polydopamine-assisted immobilization of trypsin onto monolithic structures for protein digestion," Journal of Separation Science, vol. 35, no. 12, pp. 1514-1520, 2012.

[17] H.-P. Peng, R.-P. Liang, L. Zhang, and J.-D. Qiu, "Facile preparation of novel core-shell enzyme-Au-polydopamine- $\mathrm{Fe}_{3} \mathrm{O}_{4}$ magnetic bionanoparticles for glucose sensor," Biosensors and Bioelectronics, vol. 42, no. 1, pp. 293-299, 2013.

[18] Y. Ren, J. G. Rivera, L. He, H. Kulkarni, D.-K. Lee, and P. B. Messersmith, "Facile, high efficiency immobilization of lipase enzyme on magnetic iron oxide nanoparticles via a biomimetic coating," BMC Biotechnology, vol. 11, article 63, 2011.

[19] H. Lee, J. Rho, and P. B. Messersmith, "Facile conjugation of biomolecu les onto surfaces via mussel adhesive protein inspired coatings," Advanced Materials, vol. 21, no. 4, pp. 431434, 2009.

[20] T. S. Sileika, H.-D. Kim, P. Maniak, and P. B. Messersmith, "Antibacterial performance of polydopamine-modified polymer surfaces containing passive and active components," ACS Applied Materials and Interfaces, vol. 3, no. 12, pp. 4602-4610, 2011.

[21] M. Veerapandian and K. Yun, "Functionalization of biomolecules on nanoparticles: specialized for antibacterial applications," Applied Microbiology and Biotechnology, vol. 90, no. 5, pp. 1655-1667, 2011.

[22] A.-J. Wang, Q.-C. Liao, J.-J. Feng, Z.-Z. Yan, and J.-R. Chen, "In situ synthesis of polydopamine-Ag hollow microspheres for hydrogen peroxide sensing," Electrochimica Acta, vol. 61, no. 1, pp. 31-35, 2012.

[23] M. Sureshkumar, D. Y. Siswanto, Y. C. Chen, C. K. Lee, and M. J. Wang, "Antibacterial and biocompatible surfaces based on dopamine autooxidized silver nanoparticles," Journal of Polymer Science. B. Polymer Physics, vol. 51, no. 4, pp. 303-310, 2013.

[24] P. Jierwiriyapant, H. F. Roche, and J. W. T. Bottema, Local Soybean Economies and Government Policies in Thailand and Indonesia, CGPRT Center, Bogor, Indonesia, 1992.

[25] L. Sangla, V. Tepjun, S. Pintasen, and A. Chanmuang, "Soybean: option for alternative energy production," in Proceedings of the 1st National Meeting of Soybean Crop in Thailand, pp. 315-318, 2006.

[26] S. D. Solomon, M. Bahadory, A. V. Jeyarajasingam, S. A. Rutkowsky, and C. Boritz, "Synthesis and study of silver nanoparticles," Journal of Chemical Education, vol. 84, no. 2, pp. 322-325, 2007.

[27] M. M. Bradford, "A rapid and sensitive method for the quantitation of microgram quantities of protein utilizing the principle of protein dye binding," Analytical Biochemistry, vol. 72, no. 1-2, pp. 248-254, 1976.

[28] F. J. Plou, M. Ferrer, O. M. Nuero et al., "Analysis of Tween 80 as an esterase/lipase substrate for lipolytic activity assay," Biotechnology Techniques, vol. 12, no. 3, pp. 183-186, 1998.

[29] R. Boyer, Modern Experimental Biochemistry, Benjamin Cumings, San Francisco, Calif, USA, 2000.

[30] H. J. Lee, S. G. Lee, E. J. Oh et al., "Antimicrobial polyethyleneimine-silver nanoparticles in a stable colloidal dispersion," Colloids and Surfaces B: Biointerfaces, vol. 88, no. 1, pp. 505-511, 2011.

[31] P. A. Zapataa, L. Tamayob, M. Páezb, E. Cerdab, I. Azócarb, and F. M. Rabagliatia, "Nanocomposites based on polyethylene and nanosilver particles produced by metallocenic, "in situ", polymerization: synthesis, characterization, and antimicrobial behavior," Europearn Polymer Journal, vol. 47, no. 8, pp. 15411549, 2011.

[32] B. Li, W. Liu, Z. Jiang, X. Dong, B. Wang, and Y. Zhong, "Ultrathin and stable active layer of dense composite membrane enabled by poly(dopamine)," Langmuir, vol. 25, no. 13, pp. 73687374, 2009.

[33] H. Xu, X. Shi, H. Ma, Y. Lv, L. Zhang, and Z. Mao, "The preparation and antibacterial effects of dopa-cotton/AgNPs," Applied Surface Science, vol. 257, no. 15, pp. 6799-6803, 2011.

[34] E. Navarro, F. Piccapietra, B. Wagner et al., "Toxicity of silver nanoparticles to Chlamydomonas reinhardtii," Environmental Science \& Technology, vol. 42, no. 23, pp. 8959-8964, 2008.

[35] K.-T. Kim, L. Truong, L. Wehmas, and R. L. Tanguay, "Silver nanoparticle toxicity in the embryonic zebrafish is governed by particle dispersion and ionic environment," Nanotechnology, vol. 24, no. 11, Article ID 115101, 2013.

[36] D. R. Dreyer, D. J. Miller, B. D. Freeman, D. R. Paul, and C. W. Bielawski, "Elucidating the structure of poly(dopamine)," Langmuir, vol. 28, no. 15, pp. 6428-6435, 2012.

[37] X. Wenlei and M. Ning, "Immobilized lipase on $\mathrm{Fe}_{3} \mathrm{O}_{4}$ nanoparticles as biocatalyst for biodiesel production," Energy and Fuels, vol. 23, no. 3, pp. 1347-1353, 2009.

[38] N. Canilho, J. Jacoby, A. Pasc et al., "Isocyanate-mediated covalent immobilization of Mucor miehei lipase onto SBA15 for transesterification reaction," Colloids and Surfaces B: Biointerfaces, vol. 112, pp. 139-145, 2013.

[39] N. Dizge, B. Keskinler, and A. Tanriseven, "Covalent attachment of microbial lipase onto microporous styrene-divinylbenzene copolymer by means of polyglutaraldehyde," Colloids and Surfaces B. Biointerfaces, vol. 66, no. 1, pp. 34-38, 2008.

[40] N. Dizge, B. Keskinler, and A. Tanriseven, "Biodiesel production from canola oil by using lipase immobilized onto hydrophobic microporous styrene-divinylbenzene copolymer," Biochemical Engineering Journal, vol. 44, no. 2-3, pp. 220-225, 2009.

[41] L. Freitas, P. C. M. Da Rós, J. C. Santos, and H. F. de Castro, "An integrated approach to produce biodiesel and monoglycerides by enzymatic interestification of babassu oil (Orbinya sp)," Process Biochemistry, vol. 44, no. 10, pp. 1068-1074, 2009.

[42] E. Y. Ozmen and M. Yilma, "Pretreatment of lipase with soybean oil before immobilization on beta-cyclodextrin-based polymer," Colloids and Surfaces B: Biointerfaces, vol. 69, no. 1, pp. 58-62, 2009.

[43] S. Datta, L. R. Christena, and Y. R. S. Rajaram, "Enzyme immobilization: an overview on techniques and support materials," 3 Biotech, vol. 1, no. 3, pp. 1-9, 2013.

[44] S. Al-Zuhair, M. Hasan, and K. B. Ramachandran, "Kinetics of the enzymatic hydrolysis of palm oil by lipase," Process Biochemistry, vol. 38, no. 8, pp. 1155-1163, 2003.

[45] Y. Wu, Y. Wang, G. Luo, and Y. Dai, "In situ preparation of magnetic $\mathrm{Fe}_{3} \mathrm{O}_{4}$-chitosan nanoparticles for lipase immobilization by cross-linking and oxidation in aqueous solution," Bioresource Technology, vol. 100, no. 14, pp. 3459-3464, 2009.

[46] F. Kartal and A. Kilinç, "Immobilization of pancreatic lipase on polyvinyl alcohol by cyanuric chloride," Preparative Biochemistry and Biotechnology, vol. 36, no. 2, pp. 139-151, 2006.

[47] S. K. Narwal, N. K. Saun, and R. Gupta, "Characterization and catalytic properties of free and silica-bound lipase: a comparative study," Journal of Oleo Science, vol. 63, no. 6, pp. 599-605, 2014. 
[48] C.-J. Shieh, H.-F. Liao, and C.-C. Lee, "Optimization of lipasecatalyzed biodiesel by response surface methodology, Bioresource Technology, vol. 88, no. 2, pp. 103-106, 2003.

[49] D. H. Lee, J. M. Kim, H. Y. Shin, S. W. Kang, and S. W. Kim, "Biodiesel production using a mixture of immobilized Rhizopus oryzae and Candida rugosa lipases," Biotechnology and Bioprocess Engineering, vol. 11, no. 6, pp. 522-525, 2006.

[50] J. H. Lee, D. H. Lee, J. S. Lim et al., "Optimization of the process for biodiesel production using a mixture of immobilized Rhizopus oryzae and Candida rugosa lipases," Journal of Microbiology and Biotechnology, vol. 18, no. 12, pp. 1927-1931, 2008. 

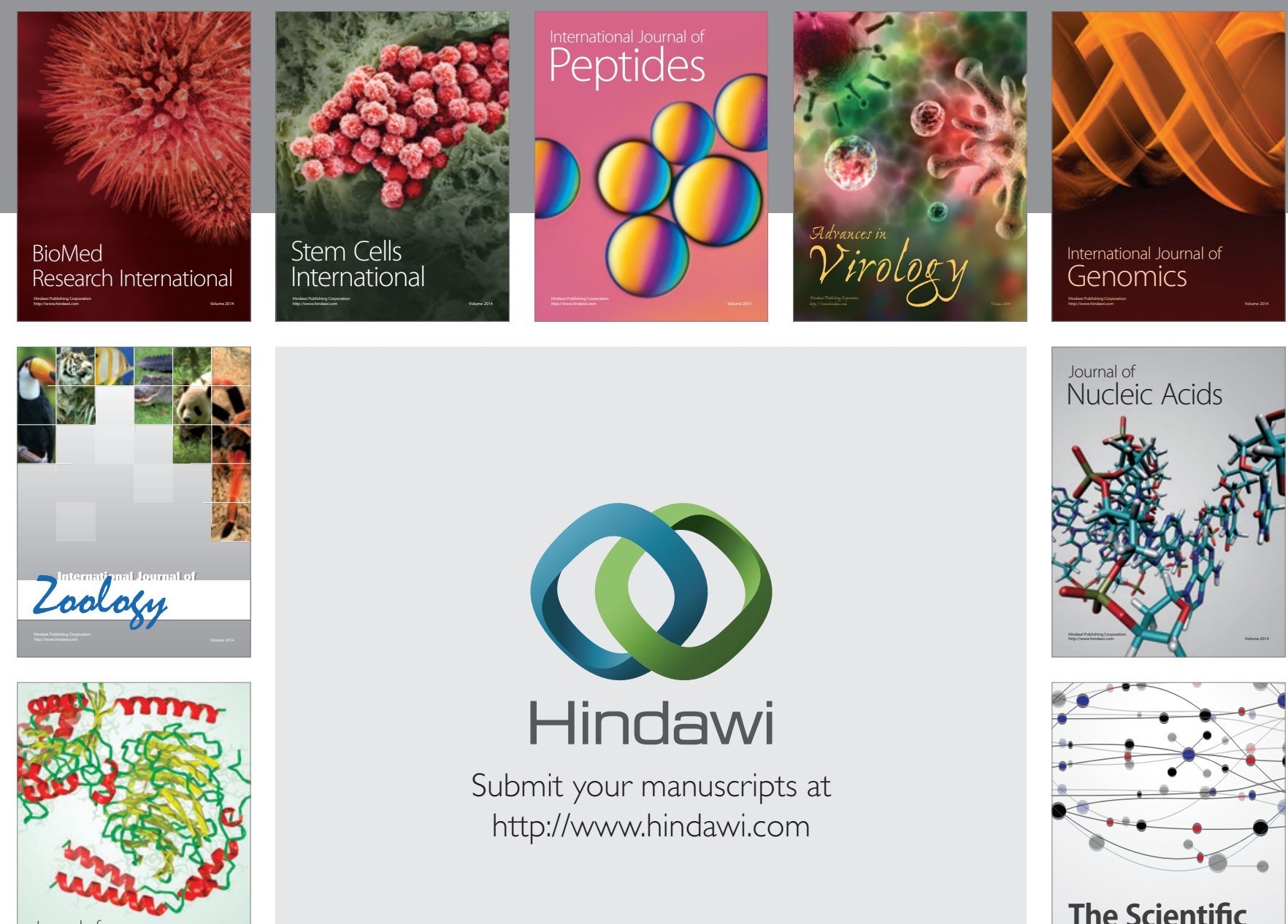

Submit your manuscripts at

http://www.hindawi.com

Journal of
Signal Transduction
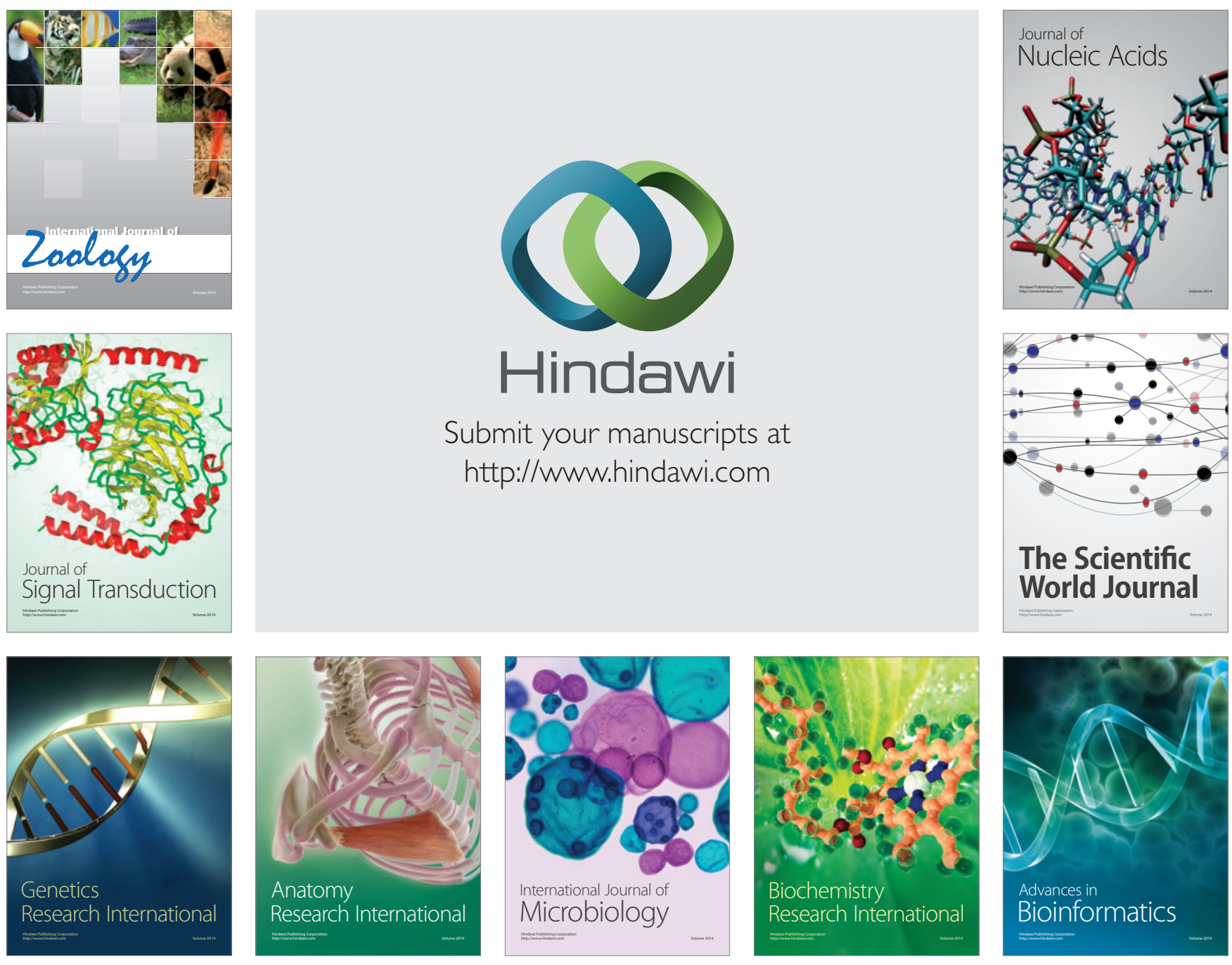

The Scientific World Journal
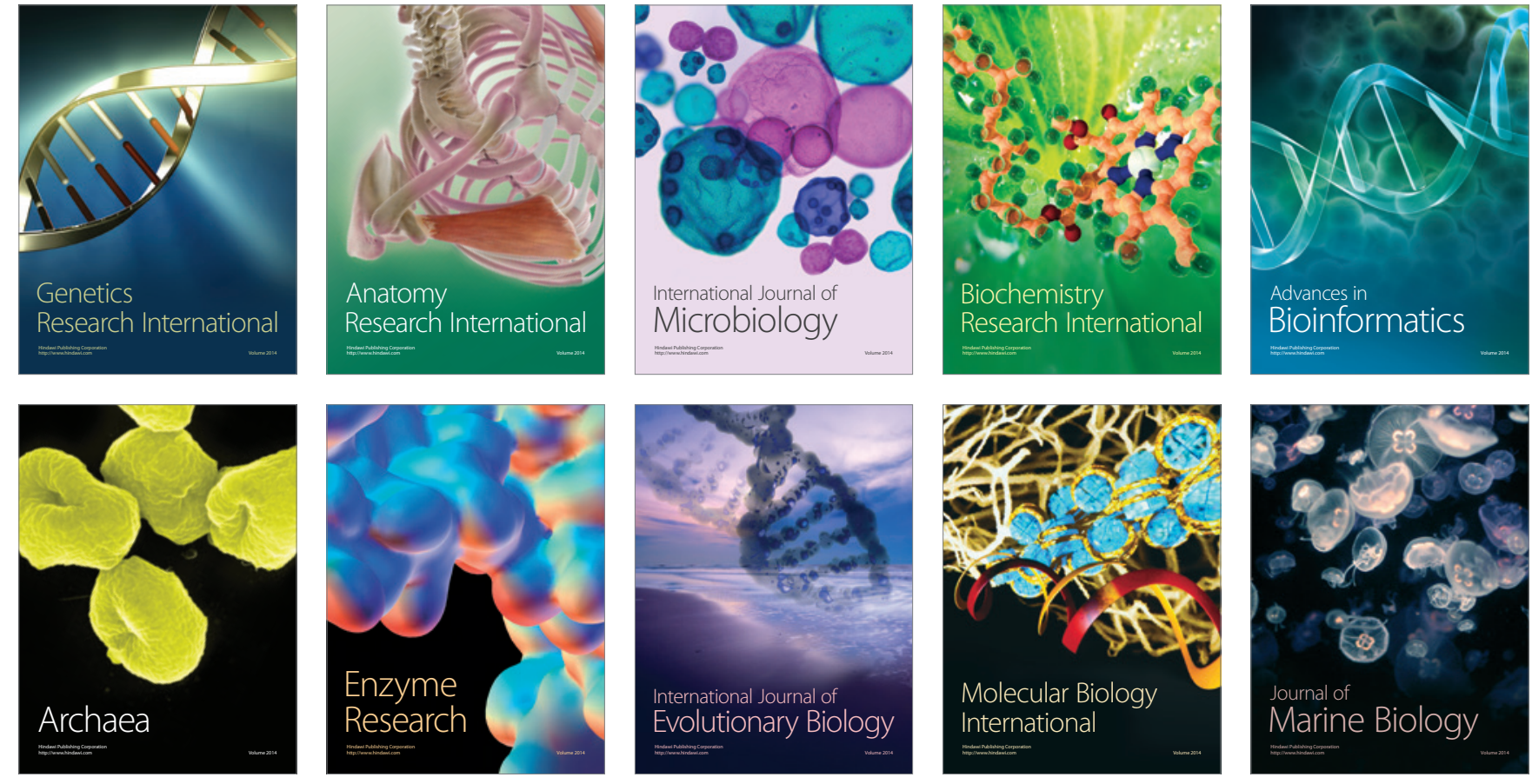